\title{
Individual health and the visibility of village economic inequality: Longitudinal evidence from native Amazonians in Bolivia
}

\author{
Eduardo A. Undurraga ${ }^{\mathrm{a}, \mathrm{b}, \dagger}$, Veronica Nica ${ }^{\mathrm{a}}$, Rebecca Zhang ${ }^{\mathrm{c}}$, Irene C. Mensah ${ }^{\mathrm{d}}$, \\ \& Ricardo A. Godoy ${ }^{\mathrm{a}}$
}

\footnotetext{
${ }^{a}$ Heller School for Social Policy and Management, Brandeis University, 415 South Street, MS035, Waltham, MA 02454-9110, USA; eundurra@brandeis.edu, nica@brandeis.edu, rgodoy@brandeis.edu.

${ }^{\mathrm{b}}$ Center for Intercultural and Indigenous Research, Pontificia Universidad Católica de Chile, Av. Vicuña Mackenna 4860, Santiago, RM 7820436, Chile; eundurra@uc.cl.

${ }^{\mathrm{c}}$ Federal Reserve Board, $20^{\text {th }}$ Street and Constitution Avenue NW, Washington, DC 20551, USA, rebeccalanzhang@gmail.com.

${ }^{\mathrm{d}}$ UNDP, 01 BP506 lot 111, Zone Residentielle, Cotonou, Republique du Benin, cocovi@brandeis.edu.
}

Keywords: Inequality; health; developing countries; rural; conspicuous consumption

JEL: D3, H4, I1; Z1

Word count: 4,193 (excluding abstract, references, figures and tables)

Abstract: 238

References: 53

Tables: 4

Figures: 1

\footnotetext{
${ }^{\dagger}$ Corresponding author. Heller School for Social Policy and Management, Brandeis University, 415 South Street, MS035, Waltham, MA 02454-9110. Telephone: +1 781736 3954, eundurra@brandeis.edu, eundurra@uc.cl
} 


\begin{abstract}
Mounting evidence suggests that income inequality is associated with worse individual health. But does the visibility of inequality matter? Using data from a horticultural-foraging society of native Amazonians in Bolivia (Tsimane'), we examined whether village inequality in resources and behaviors with greater cultural visibility are more likely to bear a negative association with health than village inequality in less conspicuous resources. We draw on a nine-year annual panel (2002-2010) from 13 Tsimane' villages for our main analysis, and an additional survey to gauge the cultural visibility of resources. We measured inequality using the Gini coefficient. We tested the robustness of our results using a shorter two-year annual panel (2008-2009) in another 40 Tsimane' villages and another measure of inequality (coefficient of variation, CV). Behaviors with low cultural visibility (e.g., household farm area planted with staples) were less likely to be associated with individual health, compared to more conspicuous behaviors (e.g., expenditures in durable goods, consumption of domesticated animals). We find some evidence that property rights and access to resources matter, with inequality of privately-owned resources showing a larger effect on health. More inequality was associated with improved perceived health - maybe due to improved health prospects from increasing wealth - and worse anthropometric indicators. For example, a unit increase in the Gini coefficient of expenditures in durable goods was associated with 0.24 fewer episodes of stress and a six percentage-point lower probability of reporting illness. A one-point increase in the $\mathrm{CV}$ of village inequality in meat consumption was associated with a 4 and 3 percentage-point lower probability of reporting illness and being in bed due to illness, and a 0.05 SD decrease in age-sex standardized arm-muscle area. In small-scale, rural societies at the periphery of market economies, nominal economic inequality in resources bore an association with individual health, but did not necessarily harm perceived health. Economic inequalities in small-scale societies apparently matter, but a thick cultural tapestry of reciprocity norms and kinship ties makes their effects less predictable than in industrial societies.
\end{abstract}


"What man dresses in purple raiment that will be shown to no one? Who feasts in secret on golden plates? Who lies down under the shade of some rural tree and displays his splendid luxury all alone? No one gets dressed up just for his own eyes, or even for a few close friends: he extends the trappings of his faults as the crowd of onlookers increases" (Lucius Annaeus Seneca)

\section{Introduction}

Several studies suggest that greater income inequality is associated with worse individual health (Deaton, 2013; Kawachi and Subramaniam, 2014; Kondo et al., 2009; Pickett and Wilkinson, 2015), but most studies have focused on people in market economies.. The main paths connecting income inequality and health include absolute income or material living standards and psychosocial and behavioral mechanisms (Lynch et al., 2000). The latter path suggests that, beyond the social gradient of health, economic inequality affects health through social comparisons and cognitive processes. These comparisons erode social capital and fuel psychosocial stress among all people in a community (contextual effects), which may harm health through several biological mechanisms (Brunner, 1997; Dickerson and Kemeny, 2004; McEwen, 2012). Social comparisons matter and may affect health even in relatively egalitarian small-scale societies (Reyes-García et al., 2008; Saidi et al., 2013; Undurraga et al., 2016; Von Rueden et al., 2014).

The evidence raises an intriguing question. If social comparisons are associated with health, does economic inequality in resources with high cultural visibility bear a stronger negative association with health than those with less cultural visibility? We examine whether individual health is affected simply by how unequal economic resources are distributed, or by the visibility of these inequalities. Based on existing evidence, we expect that more inequality will be associated with worse health outcomes and that this relationship will be stronger for more visible economic resources.

We draw on data from a horticultural-foraging society of native Amazonians in Bolivia (Tsimane'), a setting that allows us to limit unmeasured heterogeneities that plague other studies (e.g., residential segregation, ethnicity). We examine the visibility of inequality by focusing on the use of conspicuous consumption to signal prestige and status. We draw on two decades of ethnographic work and a nine-year annual panel (2002-2010) to estimate the association between various measures of individual adult health (stress, reported morbidity, consumption of alcohol 
and cigarettes, cardiovascular indicators, and anthropometric indicators of nutritional status) and the Gini coefficient of village inequality in resources that vary in their cultural visibility. We use the coefficient of variation and a shorter panel in another 40 villages to assess the robustness of our results.

\subsection{Signaling status}

To test the idea that people invest in positional goods to enhance their status, Heffetz (2011, 2012) developed the concept of socio-cultural visibility. Cultural and physical visibility need not overlap; some goods might be physically visible but might be ignorable because they carry little cultural meaning. People are socialized into different values and preferences that guide their behaviors and inclinations (Bourdieu, 1984); culture trains us to spot the observable. Heffetz based his analysis on the Consumer Expenditure Survey of the USA. He split household expenditures into 31 categories, and surveyed adults to know how long it would take them to notice a neighbor's expenditure in each of these categories. From their answers he developed a cultural visibility index, which explained $\sim 30 \%$ of the variation in total household expenditures. Since then, studies in Germany, South Africa, Indonesia, and the USA have supported his findings (Chandra et al., 2009; Friehe and Mechtel, 2014; Kaus, 2013; Roth, 2015): people spend resources to acquire goods that others notice because getting noticed enhances social status. In industrial societies, status signaling through positional goods happens because anonymous strangers cannot verify one's wealth unless one makes it noticeable (Bagwell and Bernheim, 1996; Glazer and Konrad, 1996). And status is positively associated with economic well-being (Frank, 1985), good health (Sapolsky, 2005), and reproductive success (Hudders et al., 2014; Miller, 2011; Newson, 2009). People in remote, rural societies might not need to display status through conspicuous consumption since interactions occur between people who know each other; but the need to display status will probably gain importance as traditional societies transmogrify in the face of globalization (Godoy et al., 2007a).

\subsection{The people}


The Tsimane' live in the tropical rain forest, mostly along the rivers Maniqui and Apere in the department of Beni, Bolivia. Figure 1 shows the location of the 13 villages in our panel study. The Tsimane' are a highly endogamous society, following preferential system of cross-cousin marriage (Daillant, 1994). Recent population estimates by the Tsimane' Council, their governing body, suggest that they number approximately 14,200 people, living in about 95 villages of at least eight households (Undurraga et al., 2015). A village has about 20 households (standard deviation, $\mathrm{SD}=24$ ), with an average of six people per household. 
Figure 1. Map of the 13 Tsimane' villages that participate in the annual panel study (2002-2010)

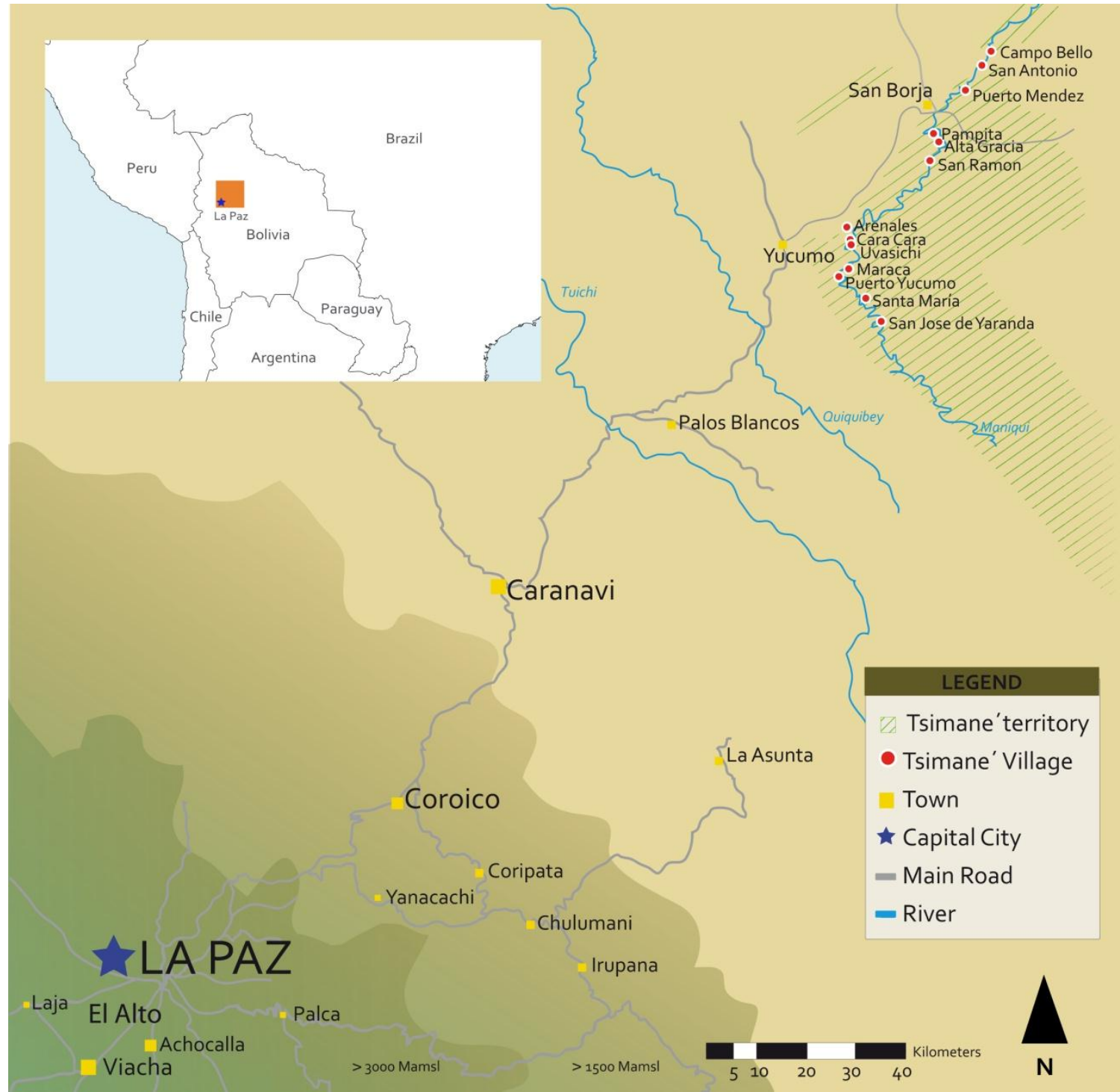

Note: The shading of the territory denotes elevation (mamsl=meters above sea level). The square symbols and letters in each town are approximately proportional in size to town population. Tsimane' villages include the 13 villages of the annual (2002-2010) Tsimane' Amazonian Panel Study (TAPS). The Tsimane' territory is an administrative division that does not reflect all the lands inhabited by the Tsimane'.

Houses lie scattered in a village, with blood and marriage-related families living around an open courtyard. Made of palms, poles, and planks, houses have four sides and, in remote villages, lack walls. In villages closer to towns, it is more common to see locks on doors and walls to enclose their homes. A survey of 13 villages in 2002 showed that in remote villages houses had an average of 2.5 walls $(\mathrm{SD}=1.6)$, but a quarter of houses had no walls. In houses 
closer to town, houses had 3.3 walls ( $\mathrm{SD}=1.2)$, and $9 \%$ of houses had no walls. Tsimane' keep many durable goods in lean-to kitchens, and $71 \%$ of these sheds had no walls. Tsimane' have a lax attitude toward asset ownership; they leave physical assets in their open courtyards so anyone can easily see what their neighbors own (Godoy and Jacobson, 1999).

In 2004 we did a survey of annual monetary expenditures and had an open-ended question about the purchase of any durable good during the previous year. People listed all expenditures in durable goods, with no restrictions on what respondents could list. When they had finished listing expenditures, we prompted their memory with items other respondents had listed. We then grouped purchases into animals, clothing, kitchen, health and hygiene, luxuries, school supplies, tools, and transport (Godoy et al., 2007a). These categories were not based on socio-cultural visibility, ubiquity, or prices, and except for luxuries, the definition and identification of a category was unambiguous to an ordinary observer. For example, we would have classified shirts as clothing, notebooks as school supplies, etc. Tsimane' allocated a higher share of expenditures to the purchase of luxuries than of to the purchase of durable utilitarian goods (e.g., cutlasses), but the study left unexplored the links between inequality, health, and the cultural salience of a resource.

We used ethnographic research to identify the range of asset wealth owned by adults. We split physical assets into domesticated animals, industrial goods acquired in the market, and locallyproduced assets. The range of goods allows one to define the relative wealth level of each adult. For example, even the most asset-poor women own chickens, fishhooks, and cotton bags, and even the most asset-poor men own bows and arrows, but only the most asset-rich people own pigs, cattle, rifles, or shotguns. We obtained a measure of asset wealth based on the village selling price of the assets, if the good was locally produced and had been sold/bartered in the village during the last month. If nobody in the village had sold/bartered the good, we imputed the price from the closest village. For goods that were rarely sold in villages (e.g. shotguns), we used the value in the nearest town. Since children own some assets (e.g., chickens), they were included when computing household wealth.

In 2009, mean daily monetary income per person among the Tsimane' reached US $\$ 0.90$ $(\mathrm{SD}=2.1)$. The mean annual village Gini coefficient of asset wealth inequality in the 13 villages of the panel study (2002-2010) was $0.31(\mathrm{SD}=0.07)$ based on household wealth and 0.49 
$(\mathrm{SD}=0.06)$ based on individual adult wealth. We found more village inequality in monetary earnings of adults (Gini=0.73) than in durable-asset wealth (Gini=0.31;0.49) because only adults (and mostly men) have access to wage earnings in logging camps or in cattle ranches, whereas everyone has access to physical assets (e.g., poultry). International studies suggest that a Gini $>0.30$ is needed before country income inequality is associated with poorer health (Kondo et al., 2009).

Tsimane' have clear concepts of private ownership, but they often borrow, share, and exchange goods and labor. Short of cash stacked away, economic resources are not exactly open for anyone to take. But they are accessible to others through multiple channels, including gifts, borrowing, and petty theft, which are made easier by a lax attitude toward planted crops and physical assets. The prevalence of gift-giving, reciprocity, sharing, and, to a lesser extent, tolerated theft as a way of buffering future consumption among native Amazonians, including the Tsimane', have been well documented (Godoy et al., 2007b; Hooper et al., 2015; Jaeggi and Gurven, 2013; Overing and Passes, 2007; Undurraga et al., 2014). Several environmental and socio-economic constraints make it hard to accumulate wealth; instead of relying on material accumulation, Tsimane' cope with mishaps through sharing and reciprocity (Undurraga et al., 2014). However, some evidence suggests that the Tsimane' have a stingy side, particularly with food (Ellis, 1996; Henrich et al., 2004), so it remains unclear whether cultural norms attenuate village inequalities or simply co-exists with them.

\section{Methods}

\subsection{Datasets}

We used two main datasets: (1) a study to measure and rank goods by their cultural visibility, and (2) an annual panel in 13 Tsimane' villages (2002-2010; hereafter long-panel). We assess the robustness of our results using a short panel (2008-2009; hereafter short-panel) in 40 different villages.

In 2006 Heffetz adapted the index of cultural visibility from the USA to the Tsimane'. Using these data, we chose six behaviors that spanned the continuum of cultural visibility and were included in our panels. Using Tsimane' rankings, we grouped behaviors into high, medium, and 
low cultural visibility. High visibility included consumption of wildlife and meat from domesticated animals. Monetary expenditures in luxuries (e.g., jewelry) and durable assets (e.g., metal tools) were classified as "medium visibility". Low visibility included forest area cleared by a household for horticulture, and household farm area planted with staples (manioc, rice, maize, plantains).

We note three caveats about the index of cultural visibility. First, the cultural visibility of a resource might vary in relation to its price, mode of acquisition, and/or ownership (e.g., individual versus communal). A resource, such as a canoe, might be nominally owned by a person, but informally shared. If so, cultural visibility might overlap with other attributes of the resource. Second, while some resources are individually owned and controlled (e.g., expenditure in luxuries), other resources might be nominally owned by the individual, but jointly managed (e.g., area planted by a household). Third, cultural visibility is not necessarily a proxy for prestige. More prestigious individuals, in principle, should be more likely to engage in highly visible behaviors, unless lower-ranking people are trying to move up the hierarchy.

Our second dataset was the long-panel. We collected annual panel data from all adults $(n=1036 ;>16$ years of age $)$ in all households $(n=401)$ of 13 villages. Adults were surveyed in a range of core topics, including: demography, asset wealth, monetary earnings, barter, reciprocity, self-perceived health and emotions, and anthropometric indicators of short and long-run nutritional status, as described elsewhere (Leonard et al., 2015).

Our robustness analysis is based on panel data collected for a randomized-controlled trial in another 40 villages (2008-2009), described elsewhere (Saidi et al., 2013; Undurraga et al., 2016). Treatments included unconditional income transfers only to the poorest households or to all households in a village, with untreated households as controls. The survey topics covered in both panels were similar, except that the short panel included cardiovascular health and finer measures of stress (Cohen et al., 1983).

\subsection{Health outcomes}

Health outcomes fell into three categories: perceived or subjective health (stress and morbidity), behavioral health (addiction), and objective health (anthropometric indicators of short-run 
nutritional status). Perceived stress and addiction proxy for psychological health; research suggests that these indicators (along with perceived morbidity) are more likely to respond in the short run to changes in economic inequality (Kawachi and Subramaniam, 2014; Pickett and Wilkinson, 2015). Table 1 shows the definition of outcomes and covariates used in the main regressions, and summary statistics for the latest (2010) survey in the long-panel.

Table 1. Definition of variables used in the regressions, and summary statistics for the latest survey (2010)

\begin{tabular}{|c|c|c|c|c|}
\hline Name & Definition & $\mathbf{N}$ & Mean & SD \\
\hline \multicolumn{5}{|c|}{ [A] Outcome variables: } \\
\hline \multicolumn{5}{|c|}{ [i] Perceived stress and perceived morbidity: } \\
\hline Stress & $\begin{array}{l}\text { "During the last } 7 \text { days how often did you feel......?" } \\
\text { Negative emotions included: sad, fear, angry, and unhappy. } \\
\text { Mean of total episodes of negative emotions used. }\end{array}$ & 607 & 4.35 & 1.33 \\
\hline Bed $^{\mathrm{a}}$ & $\begin{array}{l}\text { Person reported being bed-ridden in last } 2 \text { weeks=1; zero } \\
\text { otherwise. }\end{array}$ & 612 & 0.21 & 0.41 \\
\hline Illa $^{\mathbf{a}}$ & $\begin{array}{l}\text { Person reported having had an illness or symptom of illness in } \\
\text { last } 2 \text { weeks=1; zero otherwise. }\end{array}$ & 612 & 0.51 & 0.50 \\
\hline \multicolumn{5}{|l|}{ [ii] Addiction: } \\
\hline Addiction $^{\mathrm{b}}$ & $\begin{array}{l}\text { Principal component factor analysis used to create a } \mathrm{Z} \text { score } \\
\text { for consumption in last seven days of commercial cigarettes } \\
\text { and alcoholic beverages. }\end{array}$ & 657 & 0 & 1 \\
\hline \multicolumn{5}{|c|}{ [iii] Anthropometric indicators of nutritional status: } \\
\hline $\operatorname{Arm}(\text { muscle) })^{c}$ & $\begin{array}{l}\text { Age and sex-Z score of arm muscle area based on Frisancho } \\
(2008) \text { norms }\end{array}$ & 611 & -0.62 & 0.87 \\
\hline BMI $^{\mathrm{d}}$ & Body-mass index (weight $[\mathrm{kg}] /$ standing height $\left[\mathrm{m}^{2}\right]$ ) & 454 & 23.86 & 2.93 \\
\hline \multicolumn{5}{|c|}{ [B] Gini coefficients of village inequality $(H, M$, and $L=$ high, medium, and low visibility): } \\
\hline Wildlife & $\begin{array}{l}\text { Kg of wildlife (wild meat, fish, and birds) eaten by person in } \\
\text { last } 7 \text { days/\# of household residents. Per capita indices } \\
\text { computed from household data/household size }(\mathbf{H})\end{array}$ & 13 & 0.43 & 0.09 \\
\hline Meat & $\begin{array}{l}\text { Kg of meat from chickens, pigs, cattle, and ducks eaten by } \\
\text { person in last } 7 \text { days/\# of household residents. Per capita } \\
\text { indices computed from household data/household size }(\mathbf{H})\end{array}$ & 13 & 0.57 & 0.14 \\
\hline Durables $^{\mathrm{e}}$ & $\begin{array}{l}\text { Monetary expenditures in physical durable assets in last } 7 \text { days } \\
\text { (e.g., metal tools, plastic buckets). Per capita indices computed } \\
\text { from individual data (M) }\end{array}$ & 13 & 0.88 & 0.27 \\
\hline Luxuries & $\begin{array}{l}\text { Monetary expenditures in luxuries in last seven days (e.g., } \\
\text { watches, perfume). Per capita indices computed from } \\
\text { individual data (M) }\end{array}$ & 13 & 0.83 & 0.06 \\
\hline
\end{tabular}




\begin{tabular}{|c|c|c|c|c|}
\hline Plantings & $\begin{array}{l}\text { Hectares (ha) planted with main crops last year: manioc, rice, } \\
\text { maize, plantains. Per capita indices computed from household } \\
\text { data (L) }\end{array}$ & 13 & 0.36 & 0.06 \\
\hline Forest & $\begin{array}{l}\text { Hectares (ha) of old-growth and fallow forest cleared for } \\
\text { farming last year. Per capita indices computed from household } \\
\text { data (L) }\end{array}$ & 13 & 0.38 & 0.07 \\
\hline \multicolumn{5}{|c|}{ C] Control variables: ${ }^{f}$} \\
\hline Male & Subject's sex $($ male $=1$; female $=0)$ & 612 & 0.49 & 0.5 \\
\hline Education & Maximum school grade attained by subject & 612 & 3.0 & 2.9 \\
\hline Age & Subject's age in years & 612 & 36 & 16 \\
\hline Year & Survey year & & & \\
\hline Count & \# of times person was surveyed in panel & 612 & 7.2 & 2.6 \\
\hline
\end{tabular}

Notes: We limited the recall period for our measures of expenditures in the panel surveys to seven days for two reasons. First, we piloted several different ways of measuring socioeconomic variables. As is true in other native Amazonian societies (Gordon, 2004; Pica et al., 2004) among the Tsimane' one finds limited cultural significance for numbers (Piantadosi et al., 2014; Undurraga et al., 2013). Because of Tsimane' limited use of numbers and thus faulty recall we have found it hard to obtain reliable measures of expenditures, particularly in ordinary goods compared with salient goods. Second, because asking about expenditures and consumption over longer recall periods takes more time, we limited recall to one week in the 9-year panel study. ${ }^{\text {a }}$ The variables bed and ill capture different points in the continuum of perceived morbidity, with Bed capturing morbidity that is perceived as so severe that it restricts the person to bed and limits ordinary activities. ${ }^{b}$ We used addiction as a proxy for stress and negative emotions. Previous research suggest that economic inequalities affect mental health, including addiction (Pickett and Wilkinson, 2015), although some have argued that poorer health is rather a consequence of differing lifestyle and habits by socioeconomic status (Costa-Font et al., 2014). We also collected data on consumption of coca leaves and of a traditional home-fermented beverage (chicha), but did not include them as addictive substances. Chewing coca leaves is a highland trait that Tsimane' have adopted to relieve fatigue, hunger, and thirst when doing strenuous physical work. The consumption of chicha is a traditional form of displaying sociability, takes place at home with guests, and is associated with a festive group spirit and not with drunkenness, as is the consumption of commercial alcoholic beverages, which is often done alone. By construction, addiction has mean $=0$ and $\mathrm{SD}=1{ }^{\mathrm{c}}$ We used calipers to measure midarm muscle area following the norms of Frisancho (2008). ${ }^{\mathrm{d}} \mathrm{We}$ followed Lohman's protocol to measure standing height and body weight (Lohman et al., 1988), and excluded pregnant and lactating women (Zeng et al., 2013). Unlike other native Amazonian populations, the Tsimane' show little evidence of increased obesity (Zeng et al., 2013). Previous studies have found a significant association between BMI and wealth inequality (Carson, 2013). ${ }^{\mathrm{e}}$ The durable category includes the value of industrial goods acquired in the market, including knives, fishhooks, cutlasses, axes, and cooking pots, rifles, shotguns, fishnets, mosquito nets, radios watches, bicycles, and grinders. In contrast, locally-produced assets included the value of canoes, bows and arrows, cotton bags, grinding platforms, and wooden mortars. ${ }^{\mathrm{f}}$ Controls variables also include village-to-town travel time, annual village median of the resources whose inequality we measured, subject's level of resource k in section [B] (e.g., if regression includes Gini of luxuries, resource=person's expenditure in luxuries), total number of households in the village each year, and number of annual measures taken from the subject during the nine-years of the panel. 


\subsection{Analysis strategy}

We analyzed data using the following OLS model:

[1] $\mathrm{H}_{\mathrm{ihvtj}}=\alpha+\phi \cdot$ Inequality $_{\mathrm{vtk}}+\beta \cdot$ Resource $_{\mathrm{ihvkt}}+\theta \cdot$ Controls $_{\mathrm{ihvt}}+\varepsilon$

where $H$ stands for the health of individual $i$ of household $h$ in village $v$ at time $t ; j$ indexes for health outcome. Inequality stands for the inequality index of resource $k$ in village $v$ at time $t$. Resource stands for resource $k$ (e.g., expenditure in luxuries) of individual $i$ at time $t$. Controls included age, gender, education, travel time from village to town, median annual value of $k$ for the village, annual village population size, and number of times the person was surveyed.

We included education and level of resource $K$ to condition for the effects of economic inequality on individual health on resources that might protect health. By including median annual value of $k$ for the village and individual level of resource $K$, we are conditioning the results to the mean availability of the resource in the village in each year and also by individual consumption of that resource. We included village-to-town travel time to adjust for healthcare access, and village population as a proxy for the likelihood of social comparisons. Regressions included robust standard errors, adjusted for clustering at the village level, and year-fixed effects. As a robustness check, we followed the practice of using different measures of village economic inequality (coefficient of variation, CV) to ensure results do not hinge on how we measured inequality (De Maio, 2007; Kawachi and Kennedy, 1997; Wagstaff et al., 1991). The CV might provide a more precise measure of inequality for right-skewed distributions. In the results section, "a one-point increase" in the Gini coefficient refers to one unit in a 0-100 index (Supplementary material, Appendix A). 


\section{Results}

\subsection{Main results}

Table 2 contains two noteworthy results. First, we found evidence that village inequalities in behaviors with the least amount of cultural visibility bore no statistically significant association with health outcomes. Second, we found that greater village inequality was associated with better perceived health but worse anthropometric indicators of nutritional status. (Full regressions are shown in the Supplementary material, Appendix B.)

Table 2. Association between village economic inequality, using the Gini coefficient, and individual health indicators. Results from a nine-year panel (2002-2010) of 13 villages.

\begin{tabular}{|c|c|c|c|c|c|c|}
\hline \multirow{3}{*}{$\begin{array}{l}\text { Village } \\
\text { Gini of: }\end{array}$} & \multicolumn{6}{|c|}{ Health outcomes } \\
\hline & \multicolumn{3}{|c|}{ Perceived } & \multicolumn{3}{|c|}{ Anthropometrics } \\
\hline & Stress & Ill & Bed & Addiction & Arm & BMI \\
\hline \multicolumn{7}{|c|}{ [I]. High visibility } \\
\hline Wildlife & $0.29(0.32)$ & $-0.09(0.19)$ & $0.02(0.13)$ & $0.25(0.30)$ & $-0.43(0.34)$ & $-0.14(0.79)$ \\
\hline $\mathbf{N}$ & 3850 & 5007 & 5167 & 2888 & 4884 & 3562 \\
\hline Meat & $-0.63(0.53)$ & $-0.14(0.17)$ & $-0.13(0.11)$ & $-0.30(0.27)$ & $-0.56(0.18) * * *$ & $-1.70(0.81)^{*}$ \\
\hline $\mathbf{N}$ & 3850 & 5007 & 5167 & 2888 & 4884 & 3562 \\
\hline \multicolumn{7}{|c|}{ [II]. Medium visibility } \\
\hline Durables & $-0.24(0.13)^{*}$ & $-0.06(0.02)^{* *}$ & $-0.05(0.06)$ & $-0.001(0.06)$ & $-0.12(0.08)$ & $-0.24(0.22)$ \\
\hline $\mathbf{N}$ & 2861 & 3956 & 3956 & 2888 & 3934 & 2902 \\
\hline Luxuries & $-2.46(0.77)^{* * *}$ & $-0.22(0.09)^{* *}$ & $-0.01(0.07)$ & $-0.14(0.25)$ & $0.22(0.20)$ & $-0.28(0.55)$ \\
\hline $\mathbf{N}$ & 2861 & 3956 & 3956 & 2888 & 3934 & 2902 \\
\hline \multicolumn{7}{|c|}{ [III]. Low visibility } \\
\hline Plantings & $-0.60(0.66)$ & $-0.28(0.23)$ & $-0.02(0.23)$ & $-0.22(0.40)$ & $-0.44(0.39)$ & $-0.78(1.77)$ \\
\hline $\mathbf{N}$ & 2848 & 3925 & 3932 & 2836 & 3903 & 2895 \\
\hline Forest & $-0.01(0.71)$ & $-0.37(0.26)$ & $-0.12(0.19)$ & $-0.30(0.31)$ & $-0.68(0.45)$ & $-1.95(2.09)$ \\
\hline $\mathbf{N}$ & 3838 & 4943 & 5098 & 2839 & 4817 & 3523 \\
\hline
\end{tabular}

Notes: $* * * \mathrm{p}<.01, * * \mathrm{p}<.05, * \mathrm{p}<.10$. All regressions included robust standard errors (in parentheses) adjusted for clustering at the village level and the following covariates (coefficients not shown): year fixed effects, individuals attributes (age, sex, education, number of annual surveys in which the subject participated, and level of the economic resource, i.e., level of wildlife, meat, durables, luxuries, plantings, and forest area cleared) and village attributes (village-to-town travel time, total number of households in village, and village median of the resource, i.e., median of wildlife, meat, durables, luxuries, plantings, and forest area cleared). 
Village inequality in behaviors with low cultural visibility (area planted and deforested; Table 2, section III) bore no association with health. However, village inequalities in resources with medium visibility were significantly associated with improved self-perceived stress and illness. Last, village inequality in meat consumption (highest cultural visibility) was associated with lower anthropometrics. These results provide partial support for the hypothesis that inequality in resources with less visibility are less likely to be associated with health than more conspicuous resources. Interestingly, the inequalities most likely to be associated with individual health were those with medium cultural visibility. To illustrate the results, a one-point increase in the Gini of village inequality in meat consumption was associated with a 0.56 SD decrease in age- and sexstandardized arm-muscle area and a 1.70-point decrease in BMI. Among resources with medium visibility, a one-point increase in the Gini coefficient of village inequality in expenditures in durable goods was associated with 0.24 fewer episodes of stress and a six percentage-point lower probability of reporting illness. An increase in the Gini coefficient of village inequality in expenditure in luxuries was also associated with 2.5 fewer episodes of stress and a 22 percentage-points lower probability of reporting illness.

Table 2 also suggests that as village economic inequality increases, perceived and behavioral health improve, but anthropometric indicators weaken. An increase in the Gini coefficient of village inequality in expenditures in durable assets or luxuries was associated with lower perceived stress, lower perceived morbidity, and lower addiction. However, an increase in the Gini coefficient of village inequality in meat consumption of domesticated animals was associated with lower mid-arm muscle area and lower BMI. A decline in BMI and arm muscle area is adverse because the Tsimane' are physically fit (Zeng et al., 2013).

\subsection{Robustness}

\subsubsection{Coefficient of variation as a measure of inequality}

Table 3 shows the main coefficients for the same regressions, but using the CV instead of the Gini coefficient to measure village economic inequality. The results of Table 3 largely support the earlier results. Four of the six statistically significant coefficients in Table 2 remained 
significant and retained their sign. Irrespective of visibility, more village inequality was associated with both improved perceived health and with worse anthropometrics.

Table 3. Robustness of results: Association between village economic inequality, using the coefficient of variation (CV), and individual health indicators. Results from a nine-year panel (2002-2010) of 13 villages.

\begin{tabular}{|c|c|c|c|c|c|c|}
\hline \multirow{3}{*}{$\begin{array}{l}\text { Village } \\
\text { CV of: }\end{array}$} & \multicolumn{6}{|c|}{ Health outcomes: } \\
\hline & \multicolumn{3}{|c|}{ Perceived } & \multicolumn{3}{|c|}{ Anthropometrics } \\
\hline & Stress & Ill & Bed & Addiction & Arm & BMI \\
\hline \multicolumn{7}{|c|}{ [I]. High visibility - Coefficient of variation: } \\
\hline Wildlife & $0.05(0.10)$ & $-0.01(0.05)$ & $0.01(0.02)$ & $0.05(0.10)$ & $-0.18(0.08)^{* *}$ & $-0.06(0.21)$ \\
\hline $\mathbf{N}$ & 3850 & 5007 & 5167 & 2888 & 4884 & 3562 \\
\hline Meat & $-0.14(0.11)$ & $-0.04(0.02)^{* *}$ & $-0.03(0.01)^{* *}$ & $-0.03(0.03)$ & $-0.05(0.02)^{* *}$ & $-0.11(0.09)$ \\
\hline $\mathbf{N}$ & 3850 & 5007 & 5167 & 2888 & 4884 & 3562 \\
\hline \multicolumn{7}{|c|}{ [II]. Medium visibility - Coefficient of variation: } \\
\hline Durables & $-0.04(0.02)^{* *}$ & $-0.01(0.01)^{* *}$ & $-0.01(0.01)$ & $-0.01(0.01)$ & $-0.01(0.01)$ & $-0.02(0.03)$ \\
\hline $\mathbf{N}$ & 2861 & 3956 & 3956 & 2888 & 3934 & 2902 \\
\hline Luxuries & $-0.17(0.04)^{* * *}$ & $0.002(0.01)$ & $-0.02(0.01)$ & $-0.07(0.03)^{*}$ & $-0.02(0.03)$ & $-0.09(0.11)$ \\
\hline $\mathbf{N}$ & 2861 & 3956 & 3956 & 2888 & 3934 & 2902 \\
\hline \multicolumn{7}{|c|}{ [III]. Low visibility - Coefficient of variation: } \\
\hline Plantings & $-0.29(0.32)$ & $-0.13(0.09)$ & $-0.03(0.09)$ & $-0.13(0.15)$ & $-0.18(0.14)$ & $-0.81(0.71)$ \\
\hline $\mathbf{N}$ & 2848 & 3925 & 3932 & 2836 & 3903 & 2895 \\
\hline Forest & $-0.21(0.23)$ & $-0.14(0.07)^{*}$ & $-0.04(0.07)$ & $-0.24(0.13)^{*}$ & $-0.28(0.09)^{* *}$ & $-1.16(0.39)^{* *}$ \\
\hline $\mathbf{N}$ & 3838 & 4943 & 5098 & 2839 & 4817 & 3523 \\
\hline
\end{tabular}

Notes: $* * * \mathrm{p}<.01, * * \mathrm{p}<.05, * \mathrm{p}<.10$. All regressions included robust standard errors (in parentheses) adjusted for clustering at the village level and the following covariates (coefficients not shown): year fixed effects, individuals attributes (age, sex, education, number of annual surveys in which the subject participated, and level of economic resource) and village attributes (village-to-town travel time, village median of the resource, and total number of households in village).

However, Table 3 shows two new findings that were not apparent in Table 2. First, whereas in Table 2 behaviors with low cultural visibility bore no significant association with any health outcomes, Table 3 shows that a unit increase in the $\mathrm{CV}$ of forest area cleared was associated with a 14 percentage-point lower probability of reporting illness,, a 0.28 SD decrease in age- and sexstandardized arm-muscle area and a 1.16-point decrease in BMI, and a negative association with consumption of cigarettes and alcohol. Hence, by itself, Table 3 provides no support for the 
hypothesis that resources with lower visibility would be less likely to be associated with health. Second, we found several more significant associations among behaviors with high visibility, suggesting that our hypothesis might hinge on the measure of inequality used. Village inequality in the consumption of meat from domesticated animals also bore a negative association with stress and illness, and village inequality in the consumption of wildlife bore a negative association with arm muscle area. A one-point increase in the $\mathrm{CV}$ of village inequality in meat consumption was associated with a 4 and 3 percentage-point lower probability of reporting illness and being in bed due to illness respectively, and a 0.05 SD decrease in standardized armmuscle area. A unit increase in the $\mathrm{CV}$ of village inequality in the consumption of wildlife was associated with a 0.18 SD decrease in standardized arm-muscle area.

\subsubsection{Fresh sample and improved outcomes}

To be sure about our findings, we repeated the analysis of tables 2-3 using a larger dataset of 40 different villages measured over two years (2008-2009), including an improved measure of stress and cardiovascular health. Table 4 shows the main results the additional analysis using Gini and $\mathrm{CV}$ as indicators of inequality. 
Table 4. Robustness analysis: Association between village economic inequality, using the Gini coefficient and the coefficient of variation, and individual health indicators. Results from a twoyear panel (2008-2009) of 40 Tsimane' villages.

\begin{tabular}{|c|c|c|c|c|c|c|}
\hline \multirow{3}{*}{$\begin{array}{c}\text { Village } \\
\text { inequality } \\
\text { of }\end{array}$} & \multicolumn{6}{|c|}{ Health outcomes: } \\
\hline & \multicolumn{4}{|c|}{ Cardiovascular indicators ${ }^{\mathrm{b}}$} & \multirow[b]{2}{*}{ Addiction } & \multirow[b]{2}{*}{ BMI } \\
\hline & Stress $^{\mathrm{a}}$ & Systolic & Diastolic & Pulse rate & & \\
\hline \multicolumn{7}{|c|}{ [I]. High visibility (Gini coefficient) } \\
\hline Wildlife & $-1.07(0.54)^{*}$ & $6.90(5.91)$ & $1.21(5.88)$ & $-4.48(5.28)$ & $-0.02(0.60)$ & $0.35(1.14)$ \\
\hline $\mathbf{N}$ & 972 & 906 & 906 & 906 & 956 & 1584 \\
\hline Meat & $-0.25(0.42)$ & $-5.27(5.89)$ & $-2.8(4.69)$ & $1.65(3.49)$ & $0.34(0.38)$ & $0.76(1.04)$ \\
\hline $\mathbf{N}$ & 972 & 906 & 906 & 906 & 956 & 1584 \\
\hline
\end{tabular}

[II]. Medium visibility (Gini coefficient)

$\begin{array}{rrrrrrr}\text { Durables } & 0.02(0.17) & 5.37(3.02)^{*} & -1.02(2.23) & -2.63(1.21)^{* *} & -0.12(0.17) & 1.01(0.47)^{* *} \\ \mathbf{N} & 972 & 902 & 902 & 902 & 956 & 673 \\ \text { Luxuries } & -0.51(0.61) & 13.16(10.66) & 3.27(8.20) & 3.05(6.25) & -0.15(0.83) & 3.97(2.21)^{*} \\ \mathbf{N} & 972 & 902 & 924 & 902 & 956 & 673\end{array}$

[III]. Low visibility (Gini coefficient)

\begin{tabular}{rrrrrrr} 
Plantings & $0.50(0.35)$ & $0.24(7.18)$ & $2.15(6.46)$ & $7.29(5.59)$ & $-0.83(0.73)$ & $1.10(1.46)$ \\
$\mathbf{N}$ & 971 & 905 & 905 & 905 & 955 & 1581 \\
Forest & $0.77(0.68)$ & $-2.39(10.52)$ & $-0.81(10.86)$ & $11.53(7.31)$ & $-1.68(0.83)^{* *}$ & $0.65(1.56)$ \\
$\mathbf{N}$ & 971 & 905 & 905 & 905 & 955 & 1581 \\
\hline- & & &
\end{tabular}

\section{[IV]. High visibility (Coefficient of variation)}

$\begin{array}{rrrrrrr}\text { Wildlife } & -0.47(0.16)^{* * *} & 3.90(2.56) & 1.21(1.81) & -2.68(1.51)^{*} & -0.12(0.22) & 0.003(0.46) \\ \mathbf{N} & 972 & 906 & 906 & 906 & 956 & 1584 \\ \text { Meat } & -0.10(0.10) & 0.45(1.57) & 0.30(1.62) & -0.05(0.94) & 0.11(0.06)^{*} & 0.02(0.17) \\ \mathbf{N} & 972 & 906 & 906 & 906 & 956 & 1584\end{array}$

[V]. Medium visibility (Coefficient of variation)

$\begin{array}{rrrrrrr}\text { Durables } & -0.03(0.03) & 0.98(0.50)^{*} & -0.14(0.40) & -0.38(0.27) & -0.05(0.02)^{* *} & 0.21(0.09)^{* *} \\ \mathbf{N} & 972 & 902 & 902 & 902 & 956 & 673 \\ \text { Luxuries } & -0.07(0.04)^{*} & 1.22(0.61)^{*} & 0.31(0.47) & 0.04(0.35) & -0.01(0.04) & 0.37(0.14)^{* *} \\ \mathbf{N} & 972 & 902 & 924 & 902 & 956 & 673\end{array}$

[VI]. Low visibility (Coefficient of variation)

\begin{tabular}{rrrrrrr} 
Plantings & $0.28(0.11)^{* *}$ & $0.30(2.60)$ & $1.49(1.80)$ & $1.86(1.65)$ & $-0.19(0.24)$ & $-0.20(0.39)$ \\
$\mathbf{N}$ & 971 & 905 & 905 & 905 & 955 & 1581 \\
Forest & $0.26(0.16)$ & $-2.45(2.93)$ & $-0.62(3.17)$ & $4.12(2.30)^{*}$ & $-0.31(0.24)$ & $-0.52(0.50)$ \\
$\mathbf{N}$ & 971 & 905 & 905 & 905 & 955 & 1581 \\
\hline
\end{tabular}

Notes: $* * * \mathrm{p}<.01, * * \mathrm{p}<.05, * \mathrm{p}<.10$. All regressions included robust standard errors (in parentheses) adjusted for clustering at the village level and the following covariates (coefficients not shown): year fixed effects, 
individuals attributes (age, sex, education, and level of economic resource) and village attributes (village-totown travel time, village median of the resource, and total number of households in village), and two dummy variables, one for each of the two treatments. ${ }^{a}$ We measured cardiovascular health using the average of three consecutive measures of systolic blood pressure, diastolic blood pressure, and pulse rate. ${ }^{\mathrm{b}}$ Our measure of stress for these regressions was improved by adapting Cohen et al.'s, Perceived Stress Scale (1983), based on our ethnographic work with the Tsimane'. We asked adults how often they had experience nine negative emotions in the week before the interview. Negative emotions included having problems with sleep, feeling angry, worried, sad, ashamed, envious, harried, feeling that one did not have enough time to do all one needed to do, and feeling things were not going well.

In Table 4, as in tables 2-3, the measures of inequality based on the CV were more likely to show statistically significant results than those estimated with the Gini coefficient. For example, using CV (sections IV-VI, Table 4) we found a total of 11 statistically-significant coefficients, but only six were significant when using the Gini coefficient (I-III, Table 4). Like Tables 2-3 together, Table 4 suggest that village inequality in resources with low visibility were less likely to show statistically-significant associations with health than those with higher cultural visibility. As an additional robustness check to compare the relative importance of the visibility of inequality, we reran all the regressions presented so far, but including all inequality domains simultaneously (Supplementary material, Appendix C, tables C3 and C4). The results confirmed our finding that resources with low visibility were less likely to be associated with health outcomes.

Tables 2-3 unambiguously suggested that village inequalities were associated with better perceived health but worse anthropometrics. Table 4 shows more ambiguous results. For instance, village inequalities in durable goods or in luxuries were associated with improved BMI, but higher systolic blood pressure. Village inequality in planted area was associated with more stress and higher pulse rate (VI, Table 4). Higher levels of self-reported addiction were associated with less village inequality in forest area cleared (section III, Table 4) and durable goods (section V, Table 4), but with more inequality in village meat consumption (section IV, Table 4). 


\section{Discussion}

Our analysis showed several noteworthy results. First, we found that the index used to measure village economic inequality mattered, in accord with previous studies of inequality (De Maio, 2007; Kawachi and Kennedy, 1997). The inequality index did not change the direction of the association, but the Gini coefficient resulted in wider confidence intervals than the CV. A connected lesson relates to the value of robustness checks using a fresh sample, which allowed for a more nuanced interpretation of findings.

Second, behaviors with low visibility were less likely to be associated with health than more conspicuous behaviors. But we found no evidence of a gradient in the magnitude of these effects. Interestingly, behaviors with medium visibility were the most likely to be associated with health, probably for two reasons. Resources with medium visibility were more likely to be individually owned, whereas the use of wildlife meat and area planted or deforested have laxer property rules. People are expected to share in the success of a hunting or a fishing expedition (Gurven and Von Rueden, 2006; Undurraga et al., 2014), or to share meat (Ellis, 1996), and the same applies to area cultivated. People without enough food can surreptitiously take planted crops from others' fields. Thus, it might not be simply cultural visibility that matters, but also tenure and formal or informal access to the resource. If inequality triggers resentment, thereby harming health, then goods and behaviors with intermediate cultural visibility are the most likely culprits since people have informal access to some of each other's crops and catch from the wild. Measurement error could be another explanation. With shared resources there might have been some double counting. Consumption of shared resource $K$ might have included the amount received in gifts or pilfered. If so, we would expect some measurement error both around $K$ and village inequality in $K$, which may attenuate the effects of inequality. These errors would be less marked with privately-owned resources, of which people are more likely to know how much they own.

Third, we found an apparently ambiguous association between economic inequality and health. The results from the long-panel (tables 2-3) suggest that higher village inequality was associated with improved perceived health and worse anthropometrics, but this finding was not robust (Table 4). This ambiguity could reflect noise or omitted-variable bias, particular to each health outcome and resource inequality. For instance, unmeasured reciprocity norms might be associated with better anthropometric outcomes, but would be negatively associated with 
inequality in nominal resource ownership. If so, failure to control for these norms may attenuate the association between inequality and anthropometrics (but maybe not the association between inequality and perceived health). We reran the regressions including an indicator of whether the participant had given or received any gifts during the seven days before the survey

(Supplementary material, Appendix C, section 3.3). The results largely held, except for the regressions of the 13-village panel using CV as a measure of inequality. Despite the limitations in the reciprocity variable, four anthropometric indicators were no longer significantly associated with resource inequality, which hints at the idea that reciprocity may mediate the relation between inequality and health. Relative rank could be another confounder, although we partially controlled for rank by including the individual level of resource $K$, and elsewhere we show that rank is stable over time and has a small effect on health (Undurraga et al., 2010).

We think that a more plausible explanation for our findings relates to the differences between perceived and objective health. People's perceptions may be a relatively poor indicator of actual health (Sen, 2002), but may instead indicate perceived health prospects. Considering Tsimane' reciprocity norms and lax property rights, villages with higher inequality may be villages with increasing wealth availability, and more so for industrial goods (medium visibility). If so, the finding that higher village inequality was associated with better perceived health and worse objective outcomes should not come as a surprise. But results from Table 4 are less clear-cut. The positive association between village inequality in industrial goods and BMI (non-significant in tables 2-3) is, however, consistent with this explanation: inequality in industrial goods may signal greater availability of outside wealth.

Empirical ambiguity in results are not unique to our study. While a large literature supports the relation between community inequality and health, harmful effects of inequality are more likely when inequality is measured over large units (e.g., nations), outcomes include objective rather than subjective measures of health, outcomes have a steep social gradient, inequalities are computed from individual rather than from household data, and when using longer panels (Kawachi and Subramaniam, 2014; Kondo et al., 2009; Pickett and Wilkinson, 2015). Because each of the two datasets we used has specific strengths and shortcomings (Leonard et al., 2015; Undurraga et al., 2016), it is difficult to place more confidence in one over the other. 
Our study has several limitations. Owing to limited funds, we had to limit the panel to 13 villages and nine annual surveys. These villages vary in their levels of acculturation and market exposure. Self-reported measures of health have limitations, as has been shown elsewhere (Sen, 2002). Measures of income or expenditures in goods in a rural society such as the Tsimane', where money is of limited use, are limited compared to these same measures in societies with well-established markets. Because our study relies on observational data, our results are limited by well-known endogeneity bias. We present associations between the inequality in resources with different levels of visibility and health outcomes; it is also possible that inequalities are caused by differences in health (Deaton, 2013). Last, some variables may be problematic to identify the relation between inequality and health. For example, as is true for other native Amazonians, hunting game is a prestigious activity among the Tsimane' and is a costly investment that may bring benefits beyond nutrition (Gurven, 2004; Gurven et al., 2006). But it is also true that consuming meat has a direct effect on health, particularly considering some evidence suggesting that the Tsimane' diet is rich in carbohydrates and calories but may be poor in animal protein (Foster et al., 2005). Another example may be a potential relation between inequality and agricultural productivity; although previous studies have found little evidence to support this hypothesis (Godoy et al., 2004).

\section{Conclusions}

The main strengths of our analysis include the use of a unique dataset to rule-out common confounders, alternative measures of inequality, and two distinct samples. We went beyond the literature relating inequality and health by examining the effects of inequality in goods that varied in their cultural salience. We found evidence for the importance of the visibility of inequality, with less visible resources being less likely to show an association with health than more conspicuous resources, particularly those of medium visibility. Tenure rights and access to resources also matter, with inequality of less accessible resources showing a bigger effect on health. Last, our main results showed that inequality in various economic resources was associated with better perceived health (or health prospects) and worse objective health indicators, but results were not robust to a different sample. Large income differences in industrial nations are associated with worse health and other social problems. But this need not 
be so across societies of a different ilk. When economic inequalities intertwine with a thick tapestry of reciprocity norms and kinship ties, their effects on well-being become less predictable. Economic inequalities in small-scale societies might matter, but in ways we do not yet fully understand.

\section{Acknowledgements}

The views expressed in this article do not necessarily represent the views of the Federal Reserve Board or the United States. For support for this research we thank the Cultural Anthropology Program of the National Science Foundation and the Eunice Kennedy Shriver National Institute of Child Health and Human Development (NICHD), Vicky Liu for research assistance, Camila Garcia for help with Figure 1, and Monique Borgerhoff- Mulder for comments on an earlier draft. The study and data collection received IRB approval from Brandeis University, Northwestern University, and by the Tsimane' Council -the governing body of the Tsimane'.

Data availability. The two panel data sets are available to the public at http://heller.brandeis.edu/sustainable-international-development/tsimane/index.html. The nineyear panel contains 14 villages, but only 13 villages were surveyed annually. One village was surveyed on two occasions to assess panel attrition.

\section{References}

Bagwell, L.S., Bernheim, B.D., 1996. Veblen effects in a theory of conspicuous consumption. The American Economic Review 86, 349-373.

Bourdieu, P., 1984. Distinction: a social critique of the judgment of taste. Harvard University Press, Cambridge, MA.

Brunner, E., 1997. Socioeconomic determinants of health. Stress and the biology of inequality. British Medical Journal 314, 1472-1476.

Carson, S.A., 2013. Body mass, wealth, and inequality in the 19th century: Joining the debate surrounding equality and health. Economics \& Human Biology 11, 90-94. 
Chandra, A., Glickman, S.W., Ou, F.S., Peacock, W.F., McCord, J.K., Cairns, C.B., Peterson, E.D., Ohman, E.M., Gibler, W.B., Roe, M.T., 2009. An analysis of the Association of Society of Chest Pain Centers Accreditation to American College of Cardiology/American Heart Association Non-ST-Segment Elevation Myocardial Infarction Guideline adherence. Annals of Emergency Medicine 54, 17-25.

Cohen, S., Kamarck, T., Mermelstein, R., 1983. A global measure of perceived stress. Journal of Health and Social Behavior 24, 385-396.

Costa-Font, J., Hernández-Quevedo, C., Jiménez-Rubio, D., 2014. Income inequalities in unhealthy life styles in England and Spain. Economics \& Human Biology 13, 66-75.

Daillant, I., 1994. Sens dessus-dissous. Organisation sociale et spacial des Chimanes d'Amazonie Boliviene, Laboratoire d'ethnologie et de Sociologie Comparative. Université de Paris, Paris.

De Maio, F.G., 2007. Income inequality measures. Journal of Epidemiology \& Community Health 61, 849-852.

Deaton, A., 2013. The great escape: health, wealth, and the origins of inequality. Princeton University Press, Princeton, NJ.

Dickerson, S.S., Kemeny, M.E., 2004. Acute stressors and cortisol responses: A theoretical integration and synthesis of laboratory research. Psychological Bulletin 130, 355-391.

Ellis, R., 1996. A taste for movement. An exploration of the social ethics of the Tsimane' of lowland Bolivia, Department of Anthropology. St. Andrews University, St. Andrews, Scotland.

Foster, Z., Byron, E., Reyes - García, V., Huanca, T., Vadez, V., Apaza, L., Pérez, E., Tanner, S., Gutierrez, Y., Sandstrom, B., 2005. Physical growth and nutritional status of Tsimane'Amerindian children of lowland Bolivia. American Journal of Physical Anthropology 126, 343-351.

Frank, R.H., 1985. Choosing the right pond: human behavior and the quest for status. Oxford University Press, New York.

Friehe, T., Mechtel, M., 2014. Conspicuous consumption and political regimes: Evidence from East and West Germany. European Economic Review 67, 62-81.

Frisancho, A.R., 2008. Anthropometric standards: an interactive nutritional reference of body size and body composition for children and adults. University of Michigan Press, Ann Arbor, Michigan.

Glazer, A., Konrad, K.A., 1996. A signaling explanation for charity. The American Economic Review, 1019-1028. 
Godoy, R.A., Gurven, M., Byron, E., Reyes-Garcia, V., Keough, J., Vadez, V., Wilkie, D., Leonard, W.R., Apaza, L., Huanca, T., Perez, E., 2004. Do markets worsen economic inequalities? Kuznets in the bush. Human Ecology 32, 339-364.

Godoy, R.A., Jacobson, M., 1999. Covariates of private time preference: A pilot study among the Tsimane' Indians of the Bolivian rain forest. Evolution and Human Behavior 20, 249256.

Godoy, R.A., Reyes-Garcia, V., Huanca, T., Leonard, W.R., McDade, T., Tanner, S., Vadez, V., Seyfried, C., 2007a. Signaling by consumption in a native Amazonian society. Evolution and Human Behavior 28, 124-134.

Godoy, R.A., Reyes-Garcia, V., Huanca, T., Leonard, W.R., Olvera, R.G., Bauchet, J., Ma, Z., John, J.S., Miodowski, M., Rios, O.Z., Vadez, V., Seyfreid, C., 2007b. The role of community and individuals in the formation of social capital. Human Ecology 35, 709-721.

Gordon, P., 2004. Numerical cognition without words: Evidence from Amazonia. Science 306, 496-499.

Gurven, M., 2004. To give and to give not: The behavioral ecology of human food transfers. Behavioral and Brain Sciences 27, 543-583.

Gurven, M., Kaplan, H., Gutierrez, M., 2006. How long does it take to become a proficient hunter? Implications for the evolution of extended development and long life span. Journal of Human Evolution 51, 454-470.

Gurven, M., Von Rueden, C., 2006. Hunting, social status and biological fitness. Biodemography and Social Biology 53, 81-99.

Heffetz, O., 2011. A test of conspicuous consumption: visibility and income elasticities. Review of Economics and Statistics 93, 1101-1117.

Heffetz, O., 2012. Who sees what? Demographics and the visibility of consumer expenditures. Journal of Economic Psychology 33, 801-818.

Henrich, J., Boyd, R., Bowles, S., Camerer, C., Fehr, E., Gintis, H., 2004. Foundations of human sociality: economic experiments and ethnographic evidence from fifteen smallscale societies. Oxford University Press, New York.

Hooper, P.L., Gurven, M., Winking, J., Kaplan, H.S., 2015. Inclusive fitness and differential productivity across the life course determine intergenerational transfers in a small-scale human society. Proceedings of the Royal Society of London B: Biological Sciences 282, 20142808.

Hudders, L., De Backer, C., Fisher, M., Vyncke, P., 2014. The rival wears Prada: Luxury consumption as a female competition strategy. Evolutionary Psychology 12, 570-587. 
Jaeggi, A.V., Gurven, M., 2013. Reciprocity explains food sharing in humans and other primates independent of kin selection and tolerated scrounging: a phylogenetic metaanalysis. Proceedings of the Royal Society of London B: Biological Sciences 280, 20131615 .

Kaus, W., 2013. Conspicuous consumption and "race": Evidence from South Africa. Journal of Development Economics 100, 63-73.

Kawachi, I., Kennedy, B.P., 1997. The relationship of income inequality to mortality: Does the choice of indicator matter? Social Science \& Medicine 45, 1121-1127.

Kawachi, I., Subramaniam, S.V., 2014. Income inequality, in: Berkman, L.F., Kawachi, I., Glymour, M. (Eds.), Social Epidemiology, 2nd ed. Oxford University Press, New York, pp. 126-152.

Kondo, N., Sembajwe, G., Kawachi, I., van Dam, R.M., Subramanian, S.V., Yamagata, Z., 2009. Income inequality, mortality, and self rated health: meta-analysis of multilevel studies. British Medical Journal 339, 1178-1181.

Leonard, W.R., Reyes-García, V., Tanner, S., Rosinger, A., Schultz, A., Vadez, V., Zhang, R., Godoy, R., 2015. The Tsimane'Amazonian Panel Study (TAPS): nine years (2002-2010) of annual data available to the public. Economics \& Human Biology 19, 51-61.

Lohman, T.G., Roche, A.F., Martorell, R., 1988. Anthropometric standardization reference manual, Abridge ed. Human Kinetics Books, Champaign, Illinois.

Lynch, J.W., Smith, G.D., Kaplan, G.A., House, J.S., 2000. Income inequality and mortality: importance to health of individual income, psychosocial environment, or material conditions. British Medical Journal 320, 1200-1204.

McEwen, B.S., 2012. Brain on stress: how the social environment gets under the skin. Proceedings of the National Academy of Sciences 109, 17180-17185.

Miller, G., 2011. The mating mind: how sexual choice shaped the evolution of human nature. Anchor, New York, NY.

Newson, L., 2009. Cultural versus reproductive success: why does economic development bring new tradeoffs? American Journal of Human Biology 21, 464-471.

Overing, J., Passes, A., 2007. The anthropology of love and anger. The aesthetics of conviviality in native Amazonia. Routledge, London.

Piantadosi, S.T., Jara - Ettinger, J., Gibson, E., 2014. Children's learning of number words in an indigenous farming - foraging group. Developmental science 17, 553-563.

Pica, P., Lemer, C., Izard, W., Dehaene, S., 2004. Exact and approximate arithmetic in an Amazonian indigene group. Science 306, 499-503. 
Pickett, K.E., Wilkinson, R.G., 2015. Income inequality and health: a causal review. Social Science \& Medicine 128, 316-326.

Reyes-García, V., McDade, T.W., Molina, J.L., Leonard, W.R., Tanner, S.N., Huanca, T., Godoy, R., 2008. Social rank and adult male nutritional status: evidence of the social gradient in health from a foraging-farming society. Social Science \& Medicine 67, 21072115.

Roth, C., 2015. Conspicuous consumption and peer effects: evidence from a randomized field experiment. Unpublished Manuscript, Oxford University.

Saidi, F., Behrman, J.R., Undurraga, E.A., Godoy, R.A., 2013. Inequality, relative income, and development: field-experimental evidence from the Bolivian Amazon. TAPS Working Paper Series 78.

Sapolsky, R.M., 2005. The influence of social hierarchy on primate health. Science 308, 648652.

Sen, A., 2002. Health: perception versus observation. Self-reported morbidity has severe limitations and can be extremely misleading. British Medical Journal 324, 860-861.

Seneca, L.A., 2015. Letters on Ethics: To Lucilius. Letter 94. Translated with an introduction and commentary by Margaret Graver and A.A. Long. University of Chicago Press, Chicago.

Undurraga, E.A., Behrman, J.R., Grigorenko, E.L., Schultz, A., Yiu, J., TAPS Bolivia Study Team, Godoy, R.A., 2013. Math skills and market and non-market outcomes: evidence from an Amazonian society. Economics of Education Review 37, 138-147.

Undurraga, E.A., Behrman, J.R., Leonard, W.R., Godoy, R.A., 2016. The effects of community income inequality on health: evidence from a randomized control trial in the Bolivian Amazon. Social Science \& Medicine 149, 66-75.

Undurraga, E.A., Cruz, Z., Godoy, R.A., 2015. Demografía y territorialidad de la población Tsimane' actual, in: Reyes-García, V., Huanca, T. (Eds.), Cambio global, cambio local. La sociedad Tsimane' ante la globalización. Icaria, Institut Catala d' Antropologia., Barcelona, Spain, pp. 91-120.

Undurraga, E.A., Nyberg, C., Eisenberg, D.T.A., Magvanjav, O., Reyes-Garcia, V., Huanca, T., Leonard, W.R., McDade, T.W., Tanner, S., Vadez, V., Godoy, R., Taps Bolivia Study Team, 2010. Individual wealth rank, community wealth inequality, and self-reported adult poor health: a test of hypotheses with panel data (2002-2006) from native Amazonians, Bolivia. Medical Anthropology Quarterly 24, 522-548.

Undurraga, E.A., Zycherman, A., Yiu, J., TAPS Bolivia Study Team, Godoy, R.A., 2014. Savings at the periphery of markets: evidence from forager-farmers in the Bolivian Amazon. Journal of Development Studies 50, 288-301. 
Von Rueden, C.R., Trumble, B.C., Thompson, M.E., Stieglitz, J., Hooper, P.L., Blackwell, A.D., Kaplan, H.S., Gurven, M., 2014. Political influence associates with cortisol and health among egalitarian forager-farmers. Evolution, medicine, and public health, 122-133.

Wagstaff, A., Paci, P., Van Doorslaer, E., 1991. On the measurement of inequalities in health. Social Science \& Medicine 33, 545-557.

Zeng, W., Eisenberg, D.T.A., Rubio, K., Undurraga, E.A., Nyberg, C., Tanner, S., ReyesGarcia, V., Leonard, W.R., Castaño, J., Huanca, T., McDade, T.W., TAPS Bolivia Study Team, Godoy, R.A., 2013. Adult obesity: panel study from native Amazonians. Economics \& Human Biology 11, 227-235. 